\title{
Degeneration and Necrosis
}

National Cancer Institute

\section{Source}

National Cancer Institute. Degeneration and Necrosis. NCI Thesaurus. Code C120875.

A finding that generally has features of degeneration and necrosis. 